\title{
Investigating the minimally important difference of the Diabetes Health Profile (DHP-18) and the EQ-5D and SF-6D in a UK diabetes mellitus population
}

\author{
Brendan Mulhern $^{1^{*}}$, Keith Meadows ${ }^{2}$ \\ ${ }^{1}$ Health Economics and Decision Science, School of Health and Related Research, University of Sheffield, Sheffield, UK; \\ *Corresponding Author: b.mulhern@sheffield.ac.uk \\ ${ }^{2}$ DHP Research \& Consultancy Limited, Bloxham Mill Business Centre, Banbury, UK
}

Received 15 August 2012; revised 1 February 2013; accepted 1 May 2013

Copyright (C) 2013 Brendan Mulhern, Keith Meadows. This is an open access article distributed under the Creative Commons Attribution License, which permits unrestricted use, distribution, and reproduction in any medium, provided the original work is properly cited.

\section{ABSTRACT}

Objectives: It is important to know what patient reported outcome measure (PROM) scores relate to a meaningful change in health status across time. The aim of this study was to investigate the minimally important difference (MID) of the Diabetes Health Profile (DHP-18), EQ-5D and SF-6D in a Type 1 and Type 2 diabetes patient sample. Methods: A longitudinal dataset including a UK community sample of people with Type 1 and Type 2 diabetes was used for the analysis. A combination of anchor and distribution methods was used to investigate the MID. For the anchor based method, a global health change indicator was used if it correlated with the PROM scores at baseline and follow up. To calculate the anchor based MID, the change in PROM score for those reporting no change on the anchor was subtracted from those reporting small change. For the distribution based estimation, the 1 Standard Error of Measurement, 0.5 and 0.33 standard deviation methods were used. Results: The anchor was not correlated with the DHP-18 dimensions so was only used to estimate MID values for the EQ-5D and SF-6D. For the DHP-18, MID estimates for the Psychological Distress domain range from 6.99 to 10.59 , the Barriers to Activity domain range from 6.48 to 9.89 , and the Disinhibited Eating domain range from 7.52 to 11.39 . The EQ-5D estimations range from 0.058 to 0.158 , and the SF-6D estimations range from 0.038 to 0.081 . The $0.5 \mathrm{SD}$ and 1SEM estimations are of a similar magnitude across the three measures. Conclusions:
This study has derived a range of values for each measure that may correspond to an important change in health status. The MID values may guide researchers who are using the measures as part of their assessment of both Type 1 and Type 2 patients with diabetes mellitus.

Keywords: Minimally Important Difference; DHP-18; EQ-5D; SF-6D; Diabetes Mellitus; PROMS;

Psychometrics

\section{INTRODUCTION}

Diabetes Mellitus is a chronic condition with an estimated worldwide prevalence of approximately 284.8 million in 2010 [1]. There are two types of diabetes. Those with Type 1 diabetes are unable to produce insulin, and those with Type 2 do not produce enough insulin, or do not use the insulin produced efficiently. Complications of diabetes may include heart disease, stroke and microvascular concerns. The many health problems related to diabetes also impact on an individual's psychological functioning, which is associated with worry about diabetes-related health concerns [2,3], and daily and social activities [4], which are associated with the prevalence of health complications. Impacts on psychological and behavioural functioning and health related quality of life (HRQL) have been shown to increase as disease progression worsens and the level of related complications increases [4]. It is therefore essential to assess functioning and HRQL in diabetes alongside the assessment of related clinical factors.

There are now a range of diabetes specific patient reported outcome measures (PROMs) designed to assess 
the various constructs associated with the impact of living with diabetes and its treatment on quality of life, well-being, health status and treatment satisfaction. Many of the measures, including the Diabetes Health Profile (DHP-1; DHP-18) [5,6], Audit of Diabetes Dependent Quality of Life (ADDQoL) [7], Diabetes-39 (D-39) [8] and Diabetes Specific Quality Of Life Scale (DSQOL) $[9,10]$, have acceptable psychometric properties and are valid for use in the intended population [11,12]. Generic PROMS such as EQ-5D $[13,14]$ and SF-6D $[15,16]$ can also be used to assess the HRQL of diabetes populations (and produce a utility score based on the general populations preferences that informs the economic evaluation of new and emerging interventions to be assessed across conditions. There is some evidence that these measures may be valid for assessing many of the aspects of the quality of life of people with diabetes [17-19].

In addition to being a valid and reliable measure of the health aspects of a particular condition, a PROM must also provide a score which is interpretable. This enables the important effects of treatment or interventions to be determined. However there remains a lack of understanding as to what a PROM score represents, what is a meaningful change in an individual patient's score, and what changes in score correspond to being small, moderate and large [20].

Methods have been developed to estimate values that may be interpreted as a meaningful change in a PROM score between assessments (defined as the minimally important difference (MID)) [20-23]. To investigate the MID of a PROM, and combination of anchor and distribution based approaches is recommended [21]. Anchor based approaches involve assessing change on the PROM score in comparison to an external indicator of change in health status (which could be a global health change question, or a clinical indicator). Those reporting a change in health status on the external anchor are identified and used to predict values for change for the target PROM in comparison to those who report no change in health status on the external anchor. Anchor based methods can provide a valid representation of the MID value, but the anchors used must be correlated with the PROM for which values are being estimated [21].

Distribution based methods generate a value based on the distribution of responses within the sample, but cannot provide information on the level of change across time in comparison to an external indicator. Statistics such as the effect size, the half standard deviation and standard error of measurement (SEM) are used [24,25]. Combining values from both approaches are recommended as this allows for a more precise estimate of the range of the MID to be generated [21].

There has been limited work investigating the MID of both generic and condition specific measures in diabetes, with only one study estimating MID values for the DSQOL in a Taiwanese population [26]. In this study we aim to investigate the MID of the generic measures EQ5D and SF-6D, and the condition specific DHP-18 in a population of people with Type 1 and Type 2 diabetes in the United Kingdom.

\section{METHODS}

\subsection{Measures}

\subsubsection{DHP-18}

Developed from the 32-item DHP-1 [5] the DHP-18 [6] consists of 18 items assessing psychosocial and behavioural dysfunctioning in diabetes across three domains: Psychological Distress (PD; 6 items), Barriers to Activity (BA; 7 items) and Disinhibited Eating (DE; 5 items). The domains are based on a conceptual framework which focuses on the emotional and behavioural impact of living with diabetes. The raw scores for each domain are rescaled to a metric score between 0 and 100 which can also be converted into a norm score (with a mean of 50 and an SD of 10). This enables an assessment of a score in relation to a reference group, sample or population. Metric scores were used in this study. The DHP-18 has demonstrated high levels of reliability, validity and patient acceptability [6]. However, no previous work has investigated the MID of the instrument. The DHP-18 is the diabetes-specific outcome measure selected for the UK Department of Health Patient Reported Outcome Measures (PROMs) Pilot for Long Term Conditions in Primary Care, and has been used in multinational clinical trials, quality of life outcome research, population surveys and clinical practice. It has been adapted for use in 26 different languages and can be completed using a range of media including face to face and telephone interviews, using paper/pencil, online, and also electronic form.

\subsubsection{EQ-5D}

EQ-5D $[13,14]$ is a widely used generic measure of HRQL that is used in the assessment of the cost effectiveness of new treatments and interventions. EQ-5D assesses health across five dimensions (mobility, self care, usual activities, pain/discomfort and anxiety/depression) each with three response levels (none, some, extreme/unable). A selection of the possible 243 health states produced by the EQ-5D were valued by the UK general population to produce a single figure utility score for each health state that reflects the preferences of the population [14]. The range is the utility score is -0.594 to 1 , where one equals full health, zero equals dead, and negative values are perceived as states worse than dead. Although no previous work has investigated the MID of 
EQ-5D in diabetes, a number of studies have attempted to define the MID across a range of other conditions. Walters and Brazier [27] estimated the MID of the EQ-5D across eleven patient groups (including chronic obstructive pulmonary disease, arthritis, irritable bowel syndrome, back pain, myocardial infarction, limb reconstruction and leg ulcers) to be in the range of -0.011 to 0.140 (mean 0.074), indicating that the MID may vary across conditions and patient groups. In cancer, the MID of EQ-5D has been estimated in the range of 0.10 to 0.12 [28].

\subsubsection{SF-6D}

The SF-6D is a generic preference based measure of HRQL $[15,16]$ that is also used in the assessment of cost effectiveness. The classification system assesses health status across 6 dimensions (physical functioning, role limitations, social functioning, pain, mental health and vitality) with between 3 and 5 response levels. A selection of the possible 18,000 health states have been valued by the general population to produce a single figure utility score with a range from 0.296 to 1 . Walters and Brazier [27,29] have estimated the MID of the SF-6D across the eleven patient groups outlined in the previous section to be 0.011 to 0.097 (mean 0.041). This indicates that estimated MID values for the same patient groups differ between the two generic preference based measures.

\subsection{Sample}

A longitudinal dataset from a UK community-based postal survey carried out in one health authority area [30] was used for both the anchor and distribution based analysis. The sample used in this study included 1092 respondents with a reported diagnosis of either Type 1 (n $=93)$ or Type $2(n=999)$ diabetes who fully completed the EQ-5D, SF-6D and DHP-18 at both baseline and one year follow up. This equates to $27.7 \%$ of all people with diabetes in the health authority area (Table 1 displays the sample characteristics). At baseline, $38.8 \%$ of the sample report diabetes related health complications and this increased to $48.9 \%$ at follow up. A large majority also report co morbid health complications at baseline $(80.0 \%)$ and follow up (93.4\%), and the most common were arthritis, hypertension, high cholesterol and depression and anxiety. Data on the characteristics of people with diabetes in the health authority area who did not respond to the survey are not available.

Participants were identified from primary care diabetes patient registers, and were sent a postal questionnaire to complete with a subsequent reminder letter if the survey had not been returned. Respondents were included in the study if they were aged $\geq 18$ and were excluded if they were pregnant.
Table 1. Participant characteristics.

\begin{tabular}{|c|c|}
\hline & Dataset 1 \\
\hline$N$ & 1092 \\
\hline \multicolumn{2}{|l|}{ Diabetes type $(n, \%)$} \\
\hline Type 1 & $93(8.5)$ \\
\hline Type 2 & 999 (91.5) \\
\hline Age $(m, s d)$ & $65.12(11.3)$ \\
\hline \multicolumn{2}{|l|}{ Age (range) } \\
\hline $18-45$ & $62(5.7)$ \\
\hline $46-60$ & $291(26.8)$ \\
\hline $61-70$ & $363(33.4)$ \\
\hline $71-80$ & $287(26.3)$ \\
\hline $81+$ & $84(7.7)$ \\
\hline \multicolumn{2}{|l|}{ Gender $(n, \%)$} \\
\hline Male & $656(60.1)$ \\
\hline \multicolumn{2}{|c|}{ Diabetes management $(n, \%)$} \\
\hline Insulin & $124(11.4)$ \\
\hline Tablets \& Insulin & $97(8.9)$ \\
\hline Tablets & $608(55.7)$ \\
\hline Diet & $259(23.7)$ \\
\hline \multicolumn{2}{|c|}{ Diabetes related complications? ( $n, \%)$} \\
\hline Baseline & $424(38.8)$ \\
\hline Follow up & $534(48.9)$ \\
\hline \multicolumn{2}{|c|}{ Other health complications? ( $n, \%)$} \\
\hline Baseline & $874(80.0)$ \\
\hline Follow up & $1020(93.4)$ \\
\hline
\end{tabular}

\subsection{Investigating the MID}

\subsubsection{Anchor Based Approach}

\section{1) Testing Anchor Validity}

The external anchor used in this study was a global rating of health change (GRoC) item that can identify respondents who have experienced and self report a small but important change in health. The GRoC item assesses whether health has improved or worsened over the past 12 months on a 5 point Likert scale (much better 5), somewhat better 4), stayed the same 3), somewhat worse 2) or much worse 1)), and was administered at follow up to investigate change in health status during the study period. GRoC items previously been used as an external anchor to calculate MID estimations [27,29,31]. A small but important change on the global health item was defined by a score of $1,2,4$ or 5 with patients scoring 3 defined as reporting no change in health status.

To provide a valid estimate of the MID, it is recom- 
mended that the GRoC anchor is correlated with the baseline and follow up PROM scores at a level of at least 0.3 [21], with the correlation at follow up being greater than that at baseline. This was tested for each of the three DHP-18 domains, and the EQ-5D and SF-6D utility scores. We also assessed the pattern of the mean level of change for each of the instruments across each category of the GRoC anchor. Both of these indicators were used to establish whether the anchor was valid for estimating the MID of the population. All analysis was carried out using SPSS v19.

\section{2) Calculating the MID}

The MID was calculated by subtracting the mean change on the DHP domains for patients reporting no change on the anchors from those who report small change. This approach includes the whole sample in the calculation. In line with past work [29], the direction of the change was reversed (multiplied by minus 1) for those reporting a small negative change in HRQL (i.e. those reporting a 4 or 5 on the global health change item). Confidence intervals around the MID values were calculated using Bootstrapping techniques on 1000 subsamples were used to calculate the mean values used for the calculations, and the $95 \%$ confidence intervals for the estimated values.

\subsubsection{Distribution Based Approach}

Three commonly used distribution based methods were employed in this study to investigate values for the MID, and effect sizes were also calculated to explore the relative size of the differences between those reporting change in health on the anchor GrOC question and those reporting that health has stayed the same. The three methods used to investigate values for the MID were the Standard Error of Measurement (1SEM) [24,25], 0.5 [32] and 0.33 [28] Standard Deviation (0.5SD/0.33SD) estimations. For the 1SEM approach Eq.1 was used.

$$
\mathrm{MID}=\mathrm{SD}(\text { baseline }) * \sqrt{1-\text { a reliability coefficient }}
$$

The test-retest statistic (calculated as the correlation between the baseline and follow up dimension scores) was used as the reliability coefficient as this provides an indication of the relationship between the baseline and follow up scores, and has also been used in previous studies estimating MIDs using distribution based approaches [29,31]. Values produced using the 1SEM approach have been shown to be of a similar magnitude to both the $0.5 \mathrm{SD}$ and anchor based values across a range of studies [25,33].

The 0.5SD estimation is calculated using Eq.2, where 0.5 corresponds to a moderate effect size. This calculation has been used in a range of studies estimating the MID, including for EQ-5D and SF-6D [27,28], and is used in this study it has been shown that $0.5 \mathrm{SD}$ approxi- mates the MID for a range of PROMs across a range of conditions [34].

$$
\mathrm{MID}=0.5 * \mathrm{SD}(\text { baseline })
$$

The 0.33SD approach (calculated using Eq.3) is included here for comparability with other studies estimating the MID of EQ-5D, but evidence to support the approach is less clear.

$$
\mathrm{MID}=0.33 * \mathrm{SD}(\text { baseline })
$$

Confidence intervals for the predictions were generated using bootstrapping methods across 1000 subsamples.

We also investigated the effect size of the change in DHP-18 dimension scores for those reporting a change in health status (i.e. an improvement or deterioration), and those reporting no change on the anchor. Effect size was calculated by dividing the change on each domain between baseline and follow up by the standard deviation of the mean baseline score. This was used as a further test of the validity of the MID estimations, with values of 0.2 defined as small, 0.5 defined as moderate, and 0.8 defined as large [35].

\subsection{Sensitivity and Agreement}

To investigate sensitivity, the MID values derived from each approach were used to classify the sample based on those who demonstrated improvement, deterioration or no change according to the derived values. Cohen's kappa (that measures agreement taking into account the level of agreement expected by chance) and Kendall's tau (a measure of the strength of the dependence of two ranked variables) were used to investigate agreement between the classifications of the sample using the MID estimations.

\section{RESULTS}

\subsection{Anchor Based Approach}

The correlations between the GRoC anchor and the DHP-18, EQ-5D and SF-6D are displayed in Table 2 along with the mean scores for each measure across each GRoC anchor category. The relationship between the GRoC anchor and the mean change from baseline to follow up is displayed in Figure 1. The majority of the correlations between the DHP-18 and the GRoC anchor are significant but below the minimum recommended threshold for MID calculation of 0.3. Furthermore, there is not a consistent relationship between the GRoC categories and the mean change between baseline and follow up, with scores on the Psychological distress and Barriers to activity indicating improvement in health when the GRoC anchor indicates that health has decreased over 
Table 2. Testing anchor validity and scores on each measure by GRoC category.

\begin{tabular}{|c|c|c|c|c|c|c|c|c|c|c|}
\hline & \multicolumn{4}{|c|}{ DHP-18 } & & & \multicolumn{2}{|l|}{ EQ-5D } & \multicolumn{2}{|l|}{ SF-6D } \\
\hline & \multicolumn{2}{|c|}{ Psychological distress } & \multicolumn{2}{|c|}{ Barriers to activity } & \multicolumn{2}{|c|}{ Disinhibited eating } & \multirow[b]{2}{*}{$\mathrm{T} 1$} & \multirow[b]{2}{*}{$\mathrm{T} 2$} & \multirow[b]{2}{*}{$\mathrm{T} 1$} & \multirow[b]{2}{*}{$\mathrm{T} 2$} \\
\hline & $\mathrm{T} 1$ & $\mathrm{~T} 2$ & $\mathrm{~T} 1$ & $\mathrm{~T} 2$ & $\mathrm{~T} 1$ & $\mathrm{~T} 2$ & & & & \\
\hline Correlation with anchor (r) & $0.16^{*}$ & $0.20^{*}$ & $0.15^{*}$ & $0.23^{*}$ & 0.04 & $0.11^{*}$ & $0.26^{*}$ & $0.34^{*}$ & $0.26^{*}$ & $0.37^{*}$ \\
\hline \multicolumn{11}{|l|}{$\begin{array}{l}\text { Score overall and by change } \\
\text { in GRoC status }(\mathrm{m}, \mathrm{sd})\end{array}$} \\
\hline Overall $(\mathrm{n}=1092)$ & $\begin{array}{l}19.08 \\
(21.2)\end{array}$ & $\begin{array}{l}18.85 \\
(20.9)\end{array}$ & $\begin{array}{l}22.39 \\
(19.6)\end{array}$ & $\begin{array}{l}22.95 \\
(20.2)\end{array}$ & $\begin{array}{l}36.42 \\
(22.8)\end{array}$ & $\begin{array}{l}35.97 \\
(22.4)\end{array}$ & $\begin{array}{l}0.662 \\
(0.32)\end{array}$ & $\begin{array}{l}0.646 \\
(0.33)\end{array}$ & $\begin{array}{l}0.697 \\
(0.16)\end{array}$ & $\begin{array}{l}0.690 \\
(0.16)\end{array}$ \\
\hline Much better $(\mathrm{n}=54)$ & $\begin{array}{r}14.40 \\
(17.6)\end{array}$ & $\begin{array}{l}13.99 \\
(19.0)\end{array}$ & $\begin{array}{l}20.37 \\
(18.8)\end{array}$ & $\begin{array}{l}17.72 \\
(15.1)\end{array}$ & $\begin{array}{l}35.31 \\
(25.1)\end{array}$ & $\begin{array}{l}27.2 \\
(20.7)\end{array}$ & $\begin{array}{l}0.761 \\
(0.30)\end{array}$ & $\begin{array}{l}0.768 \\
(0.30)\end{array}$ & $\begin{array}{l}0.753 \\
(0.16)\end{array}$ & $\begin{array}{l}0.778 \\
(0.16)\end{array}$ \\
\hline Somewhat better $(\mathrm{n}=118)$ & $\begin{array}{l}19.30 \\
(21.8)\end{array}$ & $\begin{array}{l}16.34 \\
(17.3)\end{array}$ & $\begin{array}{l}23.65 \\
(19.6)\end{array}$ & $\begin{array}{l}20.42 \\
(17.1)\end{array}$ & $\begin{array}{l}37.46 \\
(22.3)\end{array}$ & $\begin{array}{l}34.75 \\
(19.8)\end{array}$ & $\begin{array}{l}0.664 \\
(0.30)\end{array}$ & $\begin{array}{l}0.695 \\
(0.28)\end{array}$ & $\begin{array}{l}0.695 \\
(0.15)\end{array}$ & $\begin{array}{l}0.725 \\
(0.15)\end{array}$ \\
\hline Stayed same $(n=673)$ & $\begin{array}{l}16.80 \\
(19.3)\end{array}$ & $\begin{array}{l}16.57 \\
(18.9)\end{array}$ & $\begin{array}{l}19.55 \\
(18.0)\end{array}$ & $\begin{array}{l}19.95 \\
(17.9)\end{array}$ & $\begin{array}{l}35.41 \\
(22.7)\end{array}$ & $\begin{array}{l}35.55 \\
(22.3)\end{array}$ & $\begin{array}{l}0.726 \\
(0.28)\end{array}$ & $\begin{array}{l}0.721 \\
(0.28)\end{array}$ & $\begin{array}{l}0.730 \\
(0.16)\end{array}$ & $\begin{array}{l}0.723 \\
(0.15)\end{array}$ \\
\hline Somewhat worse $(\mathrm{n}=212)$ & $\begin{array}{l}24.55 \\
(23.2)\end{array}$ & $\begin{array}{l}25.58 \\
(23.8)\end{array}$ & $\begin{array}{l}28.43 \\
(21.3)\end{array}$ & $\begin{array}{l}32.59 \\
(23.3)\end{array}$ & $\begin{array}{l}38.54 \\
(22.5)\end{array}$ & $\begin{array}{l}39.72 \\
(22.9)\end{array}$ & $\begin{array}{l}0.491 \\
(0.34)\end{array}$ & $\begin{array}{l}0.426 \\
(0.33)\end{array}$ & $\begin{array}{l}0.606 \\
(0.14)\end{array}$ & $\begin{array}{l}0.573 \\
(0.11)\end{array}$ \\
\hline Much worse $(\mathrm{n}=35)$ & $\begin{array}{l}36.03 \\
(31.4)\end{array}$ & $\begin{array}{l}38.10 \\
(32.4)\end{array}$ & $\begin{array}{l}39.46 \\
(23.8)\end{array}$ & $\begin{array}{l}38.64 \\
(30.2)\end{array}$ & $\begin{array}{l}41.14 \\
(23.6)\end{array}$ & $\begin{array}{l}39.05 \\
(27.4)\end{array}$ & $\begin{array}{l}0.309 \\
(0.37)\end{array}$ & $\begin{array}{l}0.191 \\
(0.40)\end{array}$ & $\begin{array}{c}0.538 \\
(0.13)\end{array}$ & $\begin{array}{l}0.506 \\
(0.11)\end{array}$ \\
\hline
\end{tabular}

*Significant at 0.01 level.

time (Figure 1). In contrast, the correlations between the GRoC and the generic measures exceeds the minimum at follow up and approaches the minimum at baseline, and Figure 1 demonstrates that as self reported global health decreases, this change is also reflected on the utility scale. Therefore, the GRoC anchor was only be used to estimate MID values for the EQ-5D and SF-6D.

The estimated anchor based and distribution based MID values are displayed in Table 3. The test-retest reliability statistics used for the 1SEM distribution method were calculated as 0.766 (PD domain), 0.746 (BA domain), 0.751 (DE domain), 0.765 (EQ-5D), and 0.761 (SF-6D).

For the DHP-18, MID estimates for the Psychological Distress domain range from 6.99 to 10.59 , the Barriers to Activity domain range from 6.48 to 9.89 , and the Disinhibited Eating domain range from 7.52 to 11.39 . The EQ-5D estimations range from 0.058 to 0.158 , and the SF-6D estimations range from 0.038 to 0.081 (the anchor based estimation is the lowest estimated value). The 0.5 SD and 1SEM estimations are of a similar magnitude across the three measures. The effect size of the change in health status over time is in the small range for all three measures.

\subsection{Agreement between the Predictions}

Table 4 displays the proportions of the sample who would be classified as demonstrating minimally important improvement or decrease in health using each of the MID values. Kappa and Kendall's tau agreement statistics are calculated for the predictions in comparison to the 1SEM approach (which is used as the comparator as an estimated MID value using the method is available for all three measures, and has been shown to be equivalent to the MID for a number of PROMs in past studies [33]. There is a reasonable level of agreement across all estimations for the three DHP dimensions and EQ-5D and SF-6D, and the 0.5SD and 1SEM approach demonstrate high levels of agreement.

\section{DISCUSSION}

In this study we have investigated the minimally important difference (MID) of the DHP-18, EQ-5D and SF-6D in a Type 1 and Type 2 community based diabetes sample, and derived a range of values for each measure that may correspond to an important change. This is the first study to investigate the MID of an English language diabetes specific PROM, and also the generic EQ-5D and SF-6D in a diabetes population. The results add to the knowledge base regarding the psychometrics of the DHP-18 and the widely used EQ-5D and SF-6D in diabetes, and what a score on each measure represents.

In future research, the MID estimations produced can provide a value against which the level of change in DHP psychosocial and behavioural functioning, and HRQL as measured by EQ-5D and SF-6D can be assessed. The estimations can also be used be used to inform sample size calculations. However, the MID estimations need to be interpreted with caution, particularly as the range of values produced classify the sample differently in terms of those who report change in health status. We recommend considering the full range of values generated for 

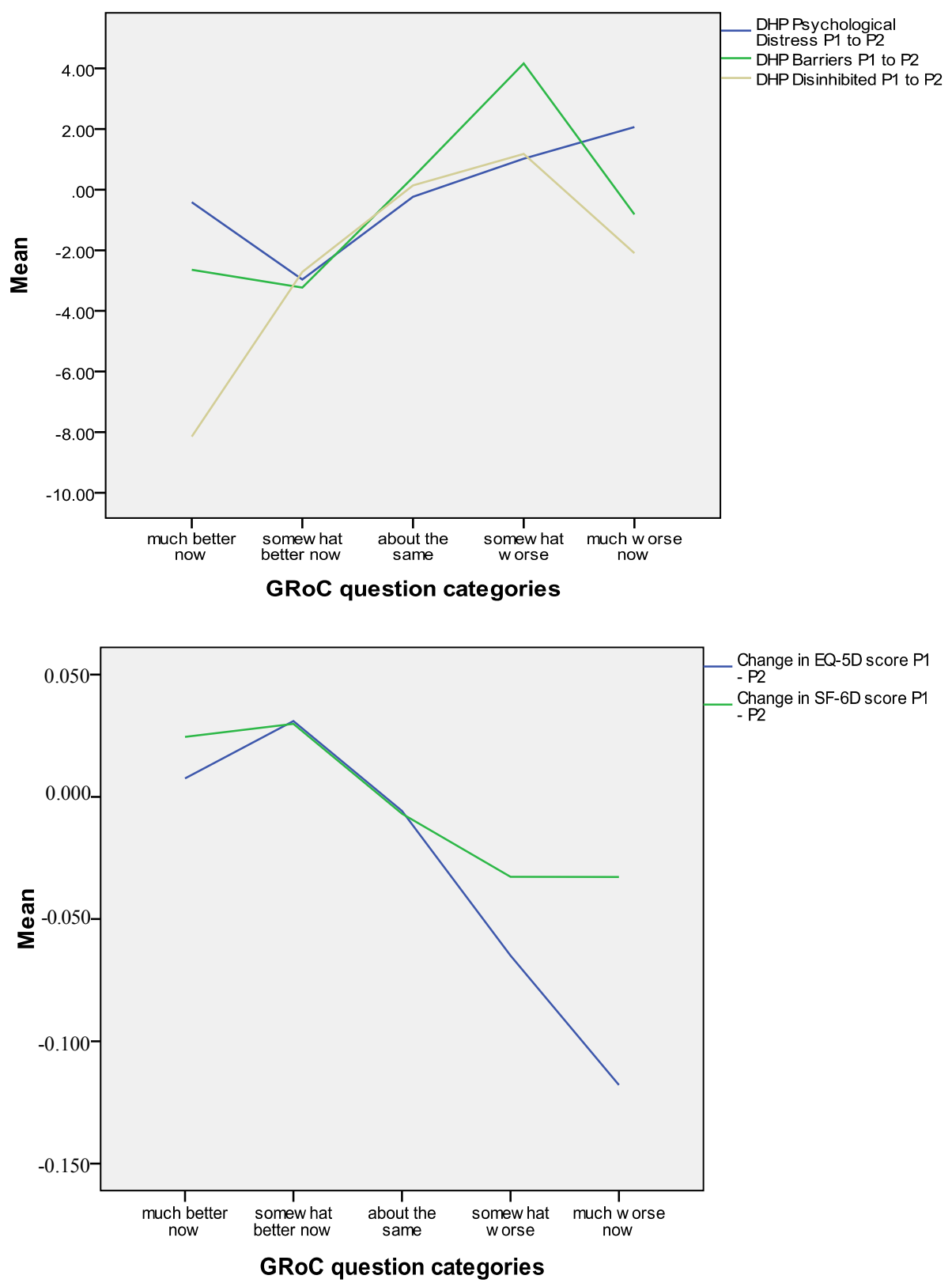

Figure 1. Mean change on each measure classified by the GRoC anchor.

each measure, as there is evidence of agreement across all estimations. However more weight may be applied to the 1SEM and 0.5SD distribution based estimations as these have the highest levels of agreement, and have been shown to be representative of the MID of a range of PROMs [32-34]. It should also be noted that the MID values derived in this study are sample specific, and further work should investigate the MID for the DHP-18 and the EQ-5D and SF-6D in other diabetes populations using a range of anchors and distribution estimation methods. Subsequently it will then be possible to review the values derived from multiple studies to investigate the validity of the estimations reported here.
A combination of anchor and distribution methods was used to investigate the MID, as there is no clear consensus regarding the best methodology to use [21]. The method of combining anchor and distribution based approaches has previously been used in a range of studies estimating the MID for PROMS across a number of conditions [27,29,36,37], including diabetes [26] where it was found that the estimation method used impacted on the values generated. This was also found in the results reported here. The anchor based approach has a level of external validity as GRoC item is assessed from the patient's perspective [38], and has been used in previous work to estimate the MID of the SF-6D [27,29]. How 
Table 3. Anchor and distribution based MID values.

\begin{tabular}{|c|c|c|c|c|c|c|c|c|c|c|}
\hline \multicolumn{5}{|c|}{ DHP-18 } & & & \multicolumn{2}{|l|}{ EQ-5D } & \multicolumn{2}{|l|}{ SF-6D } \\
\hline \multicolumn{3}{|c|}{ Method Psychological distress } & \multicolumn{2}{|c|}{ Barriers to activity } & \multicolumn{2}{|c|}{ Disinhibited eating } & \multirow[b]{2}{*}{ Prediction } & \multirow[b]{2}{*}{$95 \% \mathrm{CI}$} & \multirow[b]{2}{*}{ Prediction } & \multirow[b]{2}{*}{$95 \% \mathrm{CI}$} \\
\hline & Prediction & $95 \% \mathrm{CI}$ & Prediction & $95 \% \mathrm{CI}$ & Prediction & $95 \% \mathrm{CI}$ & & & & \\
\hline Anchor & $\mathrm{n} / \mathrm{a}$ & $\mathrm{n} / \mathrm{a}$ & $\mathrm{n} / \mathrm{a}$ & $\mathrm{n} / \mathrm{a}$ & $\mathrm{n} / \mathrm{a}$ & $\mathrm{n} / \mathrm{a}$ & 0.058 & $0.048-0.069$ & 0.038 & $0.034-0.042$ \\
\hline \multicolumn{11}{|l|}{ Distribution } \\
\hline 1SEM & 10.19 & $9.64-10.84$ & 9.89 & $9.41-10.35$ & 11.34 & $10.85-11.81$ & 0.155 & $0.146-0.161$ & 0.078 & $0.077-0.081$ \\
\hline $0.5 \mathrm{SD}$ & 10.59 & $9.96-11.21$ & 9.82 & $9.34-10.27$ & 11.39 & $10.87-11.83$ & 0.158 & $0.151-0.166$ & 0.081 & $0.079-0.083$ \\
\hline 0.33 & 6.99 & $6.57-7.40$ & 6.48 & $6.16-6.78$ & 7.52 & $7.17-7.81$ & 0.104 & $0.100-0.110$ & 0.053 & $0.052-0.055$ \\
\hline \multicolumn{11}{|l|}{ Effect size $^{1}$} \\
\hline Overall & 0.03 & & 0.05 & & 0.04 & & 0.05 & & 0.05 & \\
\hline $\begin{array}{l}\text { GRoC no change } \\
\qquad(\mathrm{n}=673)\end{array}$ & 0.01 & & 0.02 & & 0.01 & & 0.02 & & 0.04 & \\
\hline $\begin{array}{c}\text { GRoC health } \\
\text { change }(n=419)\end{array}$ & 0.05 & & 0.16 & & 0.11 & & 0.15 & & 0.20 & \\
\hline
\end{tabular}

${ }^{1}$ Using change score between baseline and follow up.

Table 4. Percentage of respondents classified as displaying minimally important health improvement or decrease by each of the predictions, and level of agreement.

\begin{tabular}{|c|c|c|c|c|c|}
\hline MID prediction & Improvement & No change & Worsening & Kappa & Tau \\
\hline \multicolumn{6}{|l|}{ DHP-18 } \\
\hline \multicolumn{6}{|l|}{ Psychological distress } \\
\hline 1SEM & 239 & 633 & 220 & & \\
\hline $0.5 \mathrm{SD}$ & 239 & 633 & 220 & 1.00 & 1.00 \\
\hline $0.33 \mathrm{SD}$ & 239 & 633 & 220 & 1.00 & 1.00 \\
\hline \multicolumn{6}{|l|}{ Barriers to activity } \\
\hline 1SEM & 150 & 766 & 176 & & \\
\hline $0.5 \mathrm{SD}$ & 150 & 766 & 176 & 1.00 & 1.00 \\
\hline $0.33 \mathrm{SD}$ & 239 & 581 & 272 & 0.70 & 0.78 \\
\hline \multicolumn{6}{|l|}{ Disinhibited eating } \\
\hline 1SEM & 241 & 597 & 254 & & \\
\hline $0.5 \mathrm{SD}$ & 241 & 597 & 254 & 1.00 & 1.00 \\
\hline $0.33 \mathrm{SD}$ & 242 & 596 & 254 & 0.99 & 0.99 \\
\hline \multicolumn{6}{|l|}{ EQ-5D } \\
\hline 1SEM & 149 & 762 & 181 & & \\
\hline $0.5 \mathrm{SD}$ & 145 & 766 & 181 & 0.99 & 0.99 \\
\hline $0.33 \mathrm{SD}$ & 252 & 637 & 203 & 0.78 & 0.84 \\
\hline Anchor & 314 & 513 & 265 & 0.61 & 0.73 \\
\hline \multicolumn{6}{|l|}{ SF-6D } \\
\hline $1 \mathrm{SEM}$ & 194 & 696 & 202 & & \\
\hline $0.5 \mathrm{SD}$ & 198 & 718 & 176 & 0.95 & 0.96 \\
\hline $0.33 \mathrm{SD}$ & 339 & 454 & 299 & 0.65 & 0.76 \\
\hline Anchor & 337 & 372 & 383 & 0.55 & 0.71 \\
\hline
\end{tabular}


ever estimations can be influenced by different anchors which may be either generic or condition specific, and using a global health change question to derive the MID for a disease specific instrument could be criticised because of a possible lack of sensitivity towards factors specific to the condition. Therefore, selecting anchors that are valid for use in the population is important, but evidence of validity is often not available. In this study the anchor based method was only used for the generic EQ-5D and SF-6D as the anchor did not correlate highly with the DHP-18. This may be because the anchor assesses general rather than diabetes specific health change (for example the low correlation between the GRoC indicator and the DE domain can be possibly explained by the fact that disinhibited eating behaviour is unlikely to impact on perceived general health change). It may be possible in future studies to use anchors that measure change in diabetes specific health status.

The distribution based approach does not directly relate to the MID, but is a valid internal measure of the level of change. When anchor based methods cannot be used, MID values derived using distribution methods can be used as an indicator of a meaningful change. The 1 SEM approach, which considers the precision of the instrument, has been shown to be related to anchor based MID estimations, and to produce similar MID values to the $0.5 \mathrm{SD}$ approach $[33,34]$, and this was found for the estimations reported here. The 0.33SD approach was included to provide a comparison, but there is less evidence for the validity of this method [28].

The MID values derived in this study for EQ-5D and SF-56D are in a similar range to those reported in other studies across a range of other conditions using anchor and distribution based methods, and this provides a level of validity to the results reported here [27-29]. Although both the EQ-5D and SF-6D are scored on the $0-1$ utility scale (measuring population preferences for health states using different descriptive systems), we found that the EQ-5D MID values are larger than those reported for SF-6D. This was also found by Walters and Brazier [27], and may be the EQ-5D has a larger range on the utility scale. The MID value produced by the anchor estimation is substantially lower than the other predictions, a finding was that was not consistently demonstrated in earlier work [27].

This study and the MID estimations derived are subject to a number of limitations. Firstly, the sample used is taken from a community based study with a response rate that is lower than is usually accepted for population health based surveys. It is therefore possible that the sample may be biased towards certain diabetes patient groups, but the data on the overall community is not available. Therefore the MID values estimated here may not be generalisable and should be used as a guide in patient groups with similar characteristics to those reported in this study. Furthermore, we were unable to assess with any degree of confidence whether the MID values for Type 1 and Type 2 diabetes differ because the Type 1 sample included was small. However using MID values derived from the combined data is valid as the EQ-5D, SF-6D and DHP-18 are used in both Type 1 and Type 2 diabetes populations. Further work should repeat the analyses reported here on a larger sample of people with Type 1 diabetes, and this will allow us to assess any potential differences in MID values between the diabetes Types. The frequency of respondents reporting a large increase or decrease in health status was also small in comparison to those reporting a small increase or decrease. Therefore we were unable to test how the anchor MID values would differ between those reporting small and large levels of health change.

In conclusion, we have investigated the MID of the condition specific DHP-18 and generic EQ-5D and SF$6 \mathrm{D}$ using both anchor and distribution based approaches. The MID values can guide researchers who are using the measures as part of their assessment of both Type 1 and Type 2 patients with diabetes mellitus.

\section{REFERENCES}

[1] International Diabetes Federation (2009) IDF Diabetes atlas. 4th Edition, International Diabetes Federation.

[2] Kohen, D., Burgess, A.P., Catalan, J. and Lant, A. (1998) The role of anxiety and depression in quality of life and symptom reporting in people with diabetes mellitus. Quality of Life Research, 7, 197-204. doi:10.1023/A:1008817812520

[3] Polonsky, W.H. (2002) Emotional and quality of life aspects of diabetes management. Current Diabetes Reports, 2, 153. doi:10.1007/s11892-002-0075-5

[4] Wexler, D.J., Grant, R.W., Wittenberg, E., Bosch, J.L., Cagliero, E., Delahanty, L., et al. (2006) Correlates of health related quality of life in type 2 diabetes. Diabetologia, 49, 1489-1497. doi:10.1007/s00125-006-0249-9

[5] Meadows, K.A., Abrams, C. and Sandbaek, A. (2000) Adaptation of the Diabetes Health Profile (DHP-1) for use with patients with type 2 diabetes mellitus: Psychometric evaluation and cross-cultural comparison. Diabetic Medicine, 17, 572-580. doi:10.1046/j.1464-5491.2000.00322.x

[6] Meadows, K.A., Steen, N., McColl, E., Eccles, M., Shields, C., Hewison, J., et al. (1996) The Diabetes Health Profile (DHP): A new instrument for assessing the psychosocial profile of insulin requiring patients-Development and psychometric evaluation. Quality of Life Research, 5, 242254. doi:10.1007/BF00434746

[7] Bradley, C., Todd, C., Gorton, T., Symonds, E., Martin, A. and Plowright, R. (1990) The development of an individualised questionnaire measure of perceived impact of diabetes on quality of life: The ADDQoL. Quality of Life 
Research, 8, 79-91. doi:10.1023/A:1026485130100

[8] Boyer, J.G. and Earp, J.A.L. (1997) The development of an instrument for assessing the quality of life of people with diabetes: Diabetes-39. Medical Care, 35, 440-453. doi:10.1097/00005650-199705000-00003

[9] Bott, U., Muhlhauser, H., Overmann, H. and Berger, M. (1998) Validation of a diabetes-specific quality-of-life scale for patients with type 1 diabetes. Diabetic Care, 21, 757-769. doi:10.2337/diacare.21.5.757

[10] Bott, U., Ebrahim, S., Hirschberger, S. and Scovlund, S.E. (2003) Effect of rapid-acting insulin analogue insulin aspart on quality of life and treatment satisfaction in patients with type 1 diabetes. Diabetic Medicine, 20, 626634. doi:10.1046/j.1464-5491.2003.01010.x

[11] Achhab, Y.E., Nejjari, C., Chikri, M. and Lyoussi, B. (2008) Disease-specific health-related quality of life instruments among adult diabetics: A systematic review. Diabetes Research and Clinical Practice, 80, 171-184. doi:10.1016/i.diabres.2007.12.020

[12] Garratt, A.M., Schmidt, L. and Fitzpatrick, R. (2002) Patient-assessed health outcome measures for diabetes: A structured review. Diabetic Medicine, 19, 1-11. doi:10.1046/j.1464-5491.2002.00650.x

[13] Brooks, R. (1996) EuroQol: The current state of play. Health Policy, 37, 53-72. doi:10.1016/0168-8510(96)00822-6

[14] Dolan, P. (1997) Modeling valuations for EuroQol health states. Medical Care, 35, 1095-1108. doi:10.1097/00005650-199711000-00002

[15] Brazier, J., Roberts, J. and Deverill, M. (2002) The estimation of a preference-based measure of health from the SF 36. Journal of Health Economics, 21, 271-292. doi:10.1016/S0167-6296(01)00130-8

[16] Brazier, J.E. and Roberts, J. (2004) Estimating a preference-based index from the SF-12. Medical Care, 42, 851859. doi:10.1097/01.mlr.0000135827.18610.0d

[17] Janssen, M.F., Lubetkin, E.L., Sekhobo, J.P. and Pickard, A.S. (2011) The use of the EQ-5D preference-based health status measure in adults with type 2 diabetes mellitus. Diabetic Medicine, 28, 395-413. doi:10.1111/j.1464-5491.2010.03136.x

[18] Solli, O., Stavem, K. and Kristiansen, I.S. (2010) Healthrelated quality of life in diabetes: The associations of complications with EQ-5D scores. Health and Quality of Life Outcomes, 8, 18. doi:10.1186/1477-7525-8-18

[19] Kontodimopoulos, N., Pappa, E., Chadjiapostolou, Z., Arvanitaki, E., Papadopoulos, A.A. and Niakas, D. (2012) Comparing the sensitivity of EQ-5D, SF-6D and 15D utilities to the specific effect of diabetic complications. European Journal of Health Economics, 13, 111-120. doi:10.1007/s10198-010-0290-y

[20] Guyatt, G.H., Osoba, D., Wu, A.W., Wyrwich, K.W. and Norman, G.R. (2002) Methods to explain the clinical significance of health status measures. Mayo Clinical Procedures, 77, 371-383. doi:10.4065/77.4.371

[21] Revicki, D., Hays, R.D., Cella, D. and Sloan, J. (2008) Recommended methods for determining responsiveness and minimally important differences for patient reported outcomes. Journal of Clinical Epidemiology, 61, 102-109. doi:10.1016/j.jclinepi.2007.03.012

[22] Turner, D., Schumemann, H.J., Griffith, L.E., Beaton, D.E., Griffiths, A.M., Critch, J.N. and Guyatt, G.H. (2010) The minimum detectable change cannot reliably replace the minimal important difference. Journal of Clinical Epidemiology, 63, 28-36. doi:10.1016/j.jclinepi.2009.01.024

[23] Wyrwich, K.W., Norquist, J.M., Lenderking, W.R. and Acaster, S. (2013) Method for interpreting change over time in patient-reported outcome measures. Quality of Life Research, 22, 475-483.

[24] Lemieux, J., Beaton, D.E., Hogg-Johnson, S., Bordeleau, L.J. and Goodwin, P.J. (2007) Three methods for minimally important difference: No relationship was found with the net proportion of patients improving. Journal of Clinical Epidemiology, 60, 448-455. doi:10.1016/j.jclinepi.2006.08.006

[25] Rejas, J., Pardo, A. and Angel Ruiz, M. (2008) Standard error of measurement as a valid alternative to minimally important difference for evaluation the magnitude of changes in patient-reported outcomes measures. Journal of Clinical Epidemiology, 61, 350-356. doi:10.1016/j.jclinepi.2007.05.011

[26] Huang, I.C., Liu, J.H., Wu, A.W., Wu, M.Y., Leite, W. and Hwang, C. (2008) Evaluating the reliability, validity, and minimal important difference of the Taiwanese version of the diabetes quality of life (DQOL) measurement. Health and Quality of Life Outcomes, 6, 87. doi:10.1186/1477-7525-6-87

[27] Walters, S.J. and Brazier, J.E. (2005) Comparison of the minimally important difference for two health state utility measures: EQ-5D and SF-6D. Quality of Life Research, 14, 1523-1532. doi:10.1007/s11136-004-7713-0

[28] Pickard, A.S., Neary, M.P. and Cella, D. (2007) Estimation of minimally important differences in EQ-5D utility and VAS scores in cancer. Health and Quality of Life Outcomes, 8, 4. doi:10.1186/1477-7525-8-4

[29] Walters, S.J. and Brazier, J.E. (2003) What is the relationship between the minimally important difference and health state utility values? The case of the SF-6D. Health and Quality of Life Outcomes, 1, 4. doi:10.1186/1477-7525-1-4

[30] Farr, A.A., Philips, C.J., Davies, S. and Morgan, S. (2010) Changes in health status of diabetic patients in Bridgend -Final report. Swansea University, Swansea.

[31] Landorf, K.B., Radford, J.A. and Hudson, S. (2010) Minimal Important Difference (MID) of two commonly used outcome measures for foot problems. Journal of Foot and Ankle Research, 3, 7. doi:10.1186/1757-1146-3-7

[32] Farivar, S.S., Liu, H. and Hays, R.D. (2004) Half standard deviation estimate of the minimally important difference in HRQOL scores? Expert Review of Pharmacoeconomics and Outcomes Research, 4, 515-523. doi:10.1586/14737167.4.5.515

[33] Crosby, R.D., Kolotkin, R.L. and Williams, G.R. (2004) An integrated method to determine meaningful changes in health-related quality of life. Journal of Clinical Epi- 
demiology, 57, 1153-1160.

doi:10.1016/j.jclinepi.2004.04.004

[34] Norman, G.R., Sloan, J.A. and Wywrich, K.W. (2003) Interpretation of changes in health-related quality of life: The remarkable universality of half a standard deviation. Medical Care, 41, 582-592.

doi:10.1097/01.MLR.0000062554.74615.4C

[35] Cohen, J. (1988) Statistical power analysis for the behavioural sciences. 2nd Edition, Lawrence Erlbaum, Hillsdale.

[36] Yost, K.J. and Eton, D.T. (2005) Combining distributionand anchor-based approaches to determine minimally important difference: The FACIT experience. Evaluation and the Health Professions, 28, 172-191. doi: $10.1177 / 0163278705275340$

[37] Shikiar, R., Harding, G., Leahy, M. and Lennox, R.D. (2005) Minimal Important Difference (MID) of the Dermatology Life Quality Index (DLQI): Results from patients with chronic idiopathic urticaria. Health and Quality of Life Outcomes, 3, 36. doi:10.1186/1477-7525-3-36

[38] Revicki, D.A., Cella, D., Hays, R.D., Sloan, J.A., Lenderking, W.R. and Aaronson, N.K. (2006) Responsiveness and minimal important differences for patient reported outcomes. Health and Quality of Life Outcomes, 4, 70. doi:10.1186/1477-7525-4-70 